\title{
Video-assisted thoracoscopic extrapleural pneumonectomy for malignant pleural mesothelioma
}

Takashi Suda, MD, Yuka Kitamura, MD, Sachiko Hasegawa, MD, Koji Negi, MD, and Yoshinobu Hattori, MD, Aichi, Japan

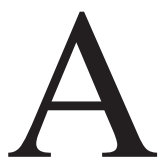

lthough extrapleural pneumonectomy is performed for malignant pleural mesothelioma, it is one of the most invasive surgical procedures in the field of thoracic surgery. Herein we describe extrapleural pneumonectomy by video-assisted thoracoscopic surgery without rib spreading as a new approach to extrapleural pneumonectomy for malignant pleural mesothelioma.

\section{Operative Technique}

The surgical procedure was performed with the patient in the lateral decubitus position with isolated lung ventilation. The operating table was flexed to expand the intercostal spaces. First, an incision of approximately $12 \mathrm{~cm}$ was made laterally along the costal arch (Figure 1). The external oblique muscle and part of the rectus abdominis muscle were incised down to the peritoneum. The peritoneum and diaphragm were separated manually. On the right side, the peritoneum and diaphragm were separated until the inferior vena cava could be observed. On the left side, they were separated up to the area close to the descending aorta and esophagus. An incision of about $4 \mathrm{~cm}$ in length was made in the midaxillary line in the fourth intercostal space. With fingers placed outside the parietal pleura, the tissues were separated in a blind fashion to the extent possible. Incisions of $1 \mathrm{~cm}$ each were made in the anterior axillary line in the sixth intercostal space and in the posterior axillary line in the eighth intercostal space. The parietal pleura was dissected in a blind fashion with fingers placed outside the parietal pleura in the same way as described previously. A working space for the thoracoscope was created in the space outside the parietal pleura by connecting the stoma. All preexisting wounds from old chest tube or pleural biopsy sites were excised. A single continuous space was made by connecting the space just created with the wound made earlier under the costal arch. By separating the diaphragm and peritoneum under the costal arch in advance, we were able to perform extrapleural dissection manually by inserting a hand through the incision made under the

\footnotetext{
From the Division of Thoracic Surgery, Fujita Health University School of Medicine, Aichi, Japan.

Received for publication Feb 7, 2007; revisions received March 2, 2007; accepted for publication March 15, 2007.

Address for reprints: T. Suda, MD, Division of Thoracic Surgery, Fujita Health University School of Medicine, 1-92 Dengakugakubo Kutsukake Toyoake, Aichi, Japan 470-1192 (E-mail: suda@fujita-hu.ac.jp).

J Thorac Cardiovasc Surg 2007;134:1088-9

$0022-5223 / \$ 32.00$

Copyright @ 2007 by The American Association for Thoracic Surgery doi:10.1016/j.jtcvs.2007.03.062
}

costal arch. Thoracoscopy was extremely useful for confirming the location of the basal part of the diaphragm, the attachment

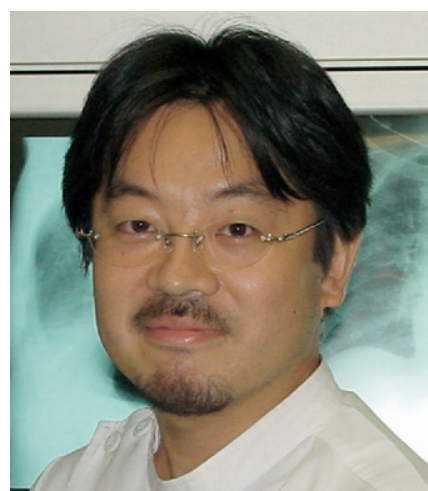

Dr Suda site of the diaphragm and chest wall, and the area where the pleura reflects. The main pulmonary artery was separated outside the mediastinal pleura and pericardium and stapled with an AutoSuture device (Ethicon Endo-Surgery, Cincinnati, Ohio). The superior and inferior pulmonary veins were divided in the pericardial cavity by the same Auto-Suture device. Before division of the main bronchus, lymph nodes below the tracheal bifurcation were
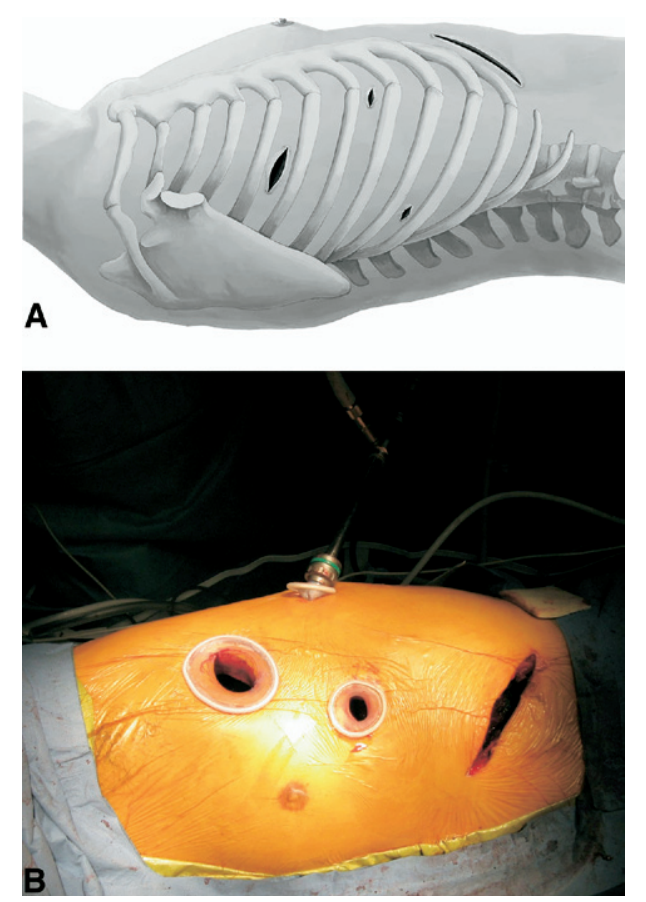

Figure 1. A, An incision of approximately $12 \mathrm{~cm}$ is made in the skin under the costal arch. An incision of $4 \mathrm{~cm}$ in the midaxillary line in the fourth intercostal space and 1-cm incisions in the anterior axillary line in the sixth intercostal space and in the posterior axillary line in the eighth intercostal space are also made. B, A rib spreader is not used and the ribs are not spread. A silicone Lap Protector mini (Hakko; Nagano, Japan) was used to protect the wound. This protector does not spread the intercostal space, but rather is used to allow the smooth insertion and withdrawal of instruments. 
TABLE 1. Demographics of patients undergoing videoassisted thoracoscopic extrapleural pneumonectomy

\begin{tabular}{|c|c|c|c|}
\hline & Patient 1 & Patient 2 & Patient 3 \\
\hline Age (y) & 68 & 78 & 72 \\
\hline Sex & Male & Male & Male \\
\hline Site & Right & Left & Left \\
\hline $\begin{array}{l}\text { Operative time } \\
\text { (min) }\end{array}$ & 650 & 623 & 696 \\
\hline $\begin{array}{l}\text { Operative blood } \\
\text { loss }(\mathrm{g})\end{array}$ & 1046 & 1495 & 1676 \\
\hline Complications & $\begin{array}{l}\text { Atrial fibrillation, } \\
\text { asthma } \\
\text { attack, and } \\
\text { gastric ulcer }\end{array}$ & $\begin{array}{l}\text { Cerebral } \\
\text { infarction }\end{array}$ & None \\
\hline Histology & Biphasic & Desmoplastic & Sarcomatoid \\
\hline IMIG stage & & & \\
\hline $\mathrm{T}$ & 3 & 4 & 3 \\
\hline $\mathrm{N}$ & 0 & 0 & 0 \\
\hline $\mathrm{M}$ & 0 & 0 & 0 \\
\hline Stage & III & IV & III \\
\hline $\begin{array}{l}\text { Follow-up } \\
\text { period (mo) }\end{array}$ & 7 & 4 & 1 \\
\hline Actual status & Alive & $\begin{array}{l}\text { Death due to } \\
\text { disease }\end{array}$ & Alive \\
\hline
\end{tabular}

IMIG, International Mesothelioma Interest Group.

dissected. The main bronchus was divided by the Auto-Suture device. With attention given to the esophagus, the tissues on the mediastinal side were separated, and the pleura, lung, diaphragm, and pericardium were resected en bloc. The resected organs were removed en bloc through the incision wound below the costal arch. Subsequently, the superior mediastinal lymph nodes were dissected. When the operation was performed on the left side, the pericardium and diaphragm were replaced by polytetrafluoroethylene sheets (Gore-Tex sheets; W. L. Gore \& Associates, Inc, Flagstaff, Ariz). For operations on the right side, the diaphragm was not reconstructed.

\section{Clinical Summary}

We first performed this operation in July 2006 and to date have performed it in 3 patients. The outcomes are presented in Table 1.
Two patients had complications. There were no surgery-related deaths.

\section{Discussion}

The mortality rate and the incidence of complications associated with extrapleural pneumonectomy are reported to be $3.6 \%$ to $30 \%$ and $19 \%$ to $50 \%$, respectively. ${ }^{1-3}$ The characteristic of our approach is that the operation is performed absolutely without spreading the ribs because thoracoscopy is used and because an incision is made under the costal arch. Thus, a reduction in postoperative pain can be expected and early postoperative ambulation is possible. We believe that early postoperative ambulation reduces postoperative complications. Despite minimal postoperative pain, 2 of the 3 patients whose cases are reported here had significant complications. However, the surgical procedure was performed safely. The postoperative complications were due to the large volume of blood lost and the high level of invasiveness of total pneumonectomy. Thoracoscopy provides a more detailed field of vision than that of open thoracotomy. It is as if the operating physician were looking into those locations directly. It is difficult to confirm the location of the pleural reflection in extrapleural pneumonectomy, but this task is easy in thoracoscopic surgery. We consider this to be a significant advantage of this surgical procedure. The operative time may be excessive. However, we believe that this approach with the thoracoscopic technique has a less invasive manner, which reduces postoperative complications, even if the operative time is long. Furthermore, there is a learning curve with any procedure and we think that the operative time will decrease with experience.

\section{References}

1. Butchart EG, Ashcroft T, Barnsley WC, Holden MP. pleuropneumonectomy in the management of diffuse malignant mesothelioma of the pleura: experience with 29 patients. Thorax. 1976;31:15-24.

2. Rusch VW, Piantadosi S, Holmes EC. The role of extrapleural pneumonectomy in malignant pleural mesothelioma. $J$ Thorac Cardiovasc Surg. 1991;102:1-9.

3. Sugarbaker DJ, Flores RM, Jaklitsch MT, Richards WG, Strauss GM, Corson JM, et al. Resection margins, extraplueural nodal status, and cell type determine postoperative long-term survival in trimodality therapy of malignant pleural mesothelioma: results of 183 patients. $J$ Thorac Cardiovasc Surg. 1999;117:54-63; discussion 63-5. 